\title{
Variant Angina: Why do you Ignore Spasm of Coronary Arteries?
}

\author{
Fumimaro Takatsu MD* \\ Department of Cardiology, Takatsu Naika Junkankika, 2-4-7 Mikawaanjo-Hommachi, Anjo, Aichi, Japan
}

\section{Introduction}

Many authors reported on variant (form of) angina (Prinzmetal's Variant Angina, vasospastic angina) till 1990s on the various aspects of this disease. However, in this century, articles on this very important disease have become very few. One reason of this apparent ignorance of vasospastic angina may be caused by a report by Cianflone et al. in 2000 [1], in which they studied only 34 patients and concluded that vasospasm is much less in Caucasian peoples. A scientific research, especially in clinical medicine, at least more than several hundred patients must be studied for some conclusion. Thus, I feel, their result is very questionable and responsibility of American Heart Association to have adopted such poor report is very large to practical medicine and all natural sciences. Why cardiologists nowadays have no concern to variant angina? As I describe below, diagnosis and treatment of patients with vasospasm are very important. In reality, it is sure that in some subjects it is very difficult to prove or deny the presence of coronary vasospasm. However, as coronary vasospasm, even in the absence of significant coronary narrowings, triggers acute myocardial infarction and fatal arrhythmias, we must be very careful to deny vasospasm. One of important problem is in medical treatment. Drugs to subjects with vasospasm are different from those patients without vasospasm (i,e. propranolol is effective to subjects with effort angina but very hazardous for patients with vasospastic angina). I am afraid ignorance of vasospasm will cause major adverse cardiac events in many patients.

\section{History and Various Aspects}

In 1959, Prinzmetal et al. reported 32 cases with ST elevation on chest pain and described one autopsy case with severe coronary atherosclerosis. Moreover, in this report, they reported that some patients showed ventricular tachycardia or complete heart block during ST elevation and suggested a role of vasospasm [2]. Prognosis of these patients was worse than those with ST depression on chest discomfort and this symptom was called as Prinzmetal's Variant Angina. A report of autopsy of 23 cases with such symptoms [3] showed severe coronary atherosclerosis in 3 patients. At present, 3 these patients are thought to have unstable angina. However, in this era, cardiologists had only electrocardiogram and further evaluation of this symptom without severe coronary atherosclerosis was impossible. In the beginning of 1970's Mason F Sones began selective coronary arteriography [4]. And Oliva et al. [5] incidentally found spontaneous coronary spasm during coronary arteriography at site without significant narrowing. In 1973, Cheng et al. [6] reported 4 cases without significant coronary narrowing and had spasm. They called these cases as "variant of the variant". In 1977, Schroeder et al. [7] and Heupler et al. [8] reported method of provocation of coronary vasospasm with ergonovine maleate during coronary arteriography and proved the cause of transient ST elevation in patients without significant coronary narrowing as transient vasospasm. And in these cases without significant coronary atherosclerosis, prognosis was thought not so poor if they have optimal medical treatment. Nowadays, emergency coronary angiography is done if chest pain with ST elevation is observed in a patient even if chest symptom and ST elevation are subsided spontaneously or with nitrate. If no significant coronary stenosis was found, the presence of coronary vasospasm is definite for cardiologists. However, I, myself, ordinarily perform provocation of spasm; if possible (once the patient returned to a ward, I explain on the vasospasm and get written informed consent), before the patient and families leave the hospital because almost all of patients and families cannot realize electrocardiographic findings and would not have medications. Moreover, although not so frequent, some patients with chest discomfort only on effort have no significant coronary narrowing have vasospasm.

\section{Complications}

Coronary vasospasm, of course, if prolonged, can cause acute myocardial infarction by itself or by causing intraluminal thrombus or rupture of minor atherosclerotic plaque. And in this respect, presence of narrowing, even less than $50 \%$, can be dangerous [9]. For preventing such prolonged spasm, it is very important to teach patients with this disease to have sublingual nitrate within their reach and to use it even if chest symptom is very mild. Prolonged spasm, other than acute coronary syndrome, causes fatal arrhythmias; ventricular fibrillation, ventricular tachycardia, completes atrioventricular block and electromechanical dissociation [10-12]. In Japan, utilization of implantable cardiac defibrillator in cases with ventricular fibrillation or ventricular tachycardia on spasm is discussed. However, I myself, consider that enough medical treatment would suppress such serious arrhythmias.

\section{Spasm associated with coronary narrowing or occlusion}

Since the end of 1970s intracoronary thrombolysis was introduced for the treatment of subjects suffering acute myocardial infarction or unstable angina; next, emergency percutaneous coronary angioplasty and in these 20 years emergency stent is done routinely. Of course, emergency bypass surgery has been done if indicated. Many of these patients have chest discomfort at rest or during sleep as symptoms of severe coronary narrowing. It is very important to resolve severe coronary narrowing(s) or occlusion as soon as possible. However, we should not rule out the possibility of coronary vasospasm because chest symptom not related to effort may be caused by spasm $[13,14]$. Except for patients with acute coronary syndrome, many patients with chest discomfort only on exercise in mornings have coronary vasospasm [15], although they also may have severe coronary narrowing. Chest discomfort on sudden cold exposure is one of specific symptoms of this disease.

Consequently, if possible, we must perform provocation of spasm several months after emergency treatment of critical coronary lesions in all patients. Thus, if such patients had bypass surgery, cardiologists

*Corresponding author: Fumimaro Takatsu MD, *Department of Cardiology, Takatsu Naika Junkankika, 2-4-7 Mikawaanjo-Hommachi, Anjo, Aichi, Japan, Tel: +81-566-71-3335; Fax: +81-566-71-3330; E-mail: takatsu-ric@grace.ocn.ne.jp

Received May 07, 2015; Accepted May 20, 2015; Published May 25, 2015

Citation: Fumimaro Takatsu MD (2015) Variant Angina: Why do you Ignore Spasm of Coronary Arteries?. Cardiol Pharmacol 4: 143. doi:10.4172/2329-6607.1000143

Copyright: ( 2015 Fumimaro Takatsu MD et al. This is an open-access article distributed under the terms of the Creative Commons Attribution License, which permits unrestricted use, distribution, and reproduction in any medium, provided the original author and source are credited. 
must alarm cardiac surgeons that, if possible, on the angiographic study to confirm patency of the bypass, provocation of spasm should be performed; almost all cardiac surgeons have no concern on vasospasm. Of course, as provocative test is, if it is done by immature cardiologists dangerous [16], experienced cardiologists should be present in the catheterization room and we must check function of direct current countershock tool just before angiographic study.

\section{Diagnosis}

I experienced over 4,000 patients with coronary vasospasm. However, some subjects who have chest discomfort suggestive of vasospastic angina show no spasm even with ergonovine or acetylcholine. And it is not so rare that in the first coronary angiography no vasospasm was induced, angiography several years later proves vasospasm. I know at least 2 patients whose electrography, incidentally showed ST elevation on chest discomfort whose repeated angiographies could not prove vasospasm. As we cannot know the true incidence of vasospasm, it is very difficult to estimate the rate of "false negative response" on the angiographic study. But we feel that $5-10 \%$ patients with vasospasm do not show spasm on any provocative test. Even with Holter electrocardiogram (ordinarily $24 \mathrm{hrs}$ of electrocardiogram recording) or implanted USB type (Medtronic co.) recording system, which can record electrocardiogram over one month, if no spasm occurs during recordings, we cannot deny the presence of vasospasm. Moreover, if spasm occurs in circumflex artery or not occlusive: 80$90 \%$, electrocardiogram, when the patient has chest discomfort, may show no changes. Thus, as sublingual nitroglycerin is very cheap, its efficacy may be one of best diagnostic method. One of important aspect of this syndrome is, in my experience, chest pain arises after several hours after drink in 5-10\% of patients of vasospastic angina. Since 1975 when I first experienced vasospasm in a patient without coronary narrowing I have followed about 1,500 patients without significant narrowing. Among them, 98 patients had chest pain several hours after drink and 3 subjects died suddenly after drink [17-19]. Although not so frequent, connection of coronary artery, which is usually observed as collateral to the vessel with more than $90 \%$ narrowing, is seen in angiogram of patients without significant narrowing. I reported this phenomenon is specific in vasospasm and even if various methods failed to proof spasm, almost all of these patients should be thought to have vasospasm [20]. In some patients, sudden exposure to cold causes chest discomfort.

\section{Methods of Provocation of Vasospasm}

For the diagnostic arteriography patients are ordinarily hospitalized at least 24 hours before catheterization because after enough explanation we must have written informed consent on the benefit and risk of the study including spasm provocation. Hospitalization is also useful to evaluate lipids profiles and blood glucose measurement.

If the patient is already given calcium antagonist for hypertension or suspected vasospasm, it should be replaced to other drugs i.e, angiotensin receptor blocker and /or short acting calcium blocker because long acting calcium blockers strongly affect the result of provocative test. In patients with frequent chest pain, I always train them how to use sublingual nitrate and give 10-20 tablets. For safety, I use oral or transdermal long acting nitrate until they are carried into catheterization room, especially when we stop calcium antagonists for evaluation of coronary vasospasm. If they have history of headache with long acting nitrate, nicorandil $10-15 \mathrm{mg}$ a day is given till the morning of the study, which, due to its short action, would not affect evaluation of vasospasm.

\section{Ergonovine : ergnovine maleate or methyl ergonovine}

In 1977 Schroeder et al. [7] first reported 57 cases and proved transient occlusion of coronary artery in 13 patients using ergonovine maleate during diagnostic coronary angiography. In their report, provocation of spasm was performed after ordinary angiography and left ventriculogaphy using sublingual nitroglycerin. Amount of ergonovine was $0.05 \mathrm{mg}$ at first and if no spasm induced, $0.10 \mathrm{mg}$ was added and finally $0.15 \mathrm{mg}$ was injected. Heupler et al. [8] proved vasospasm with intra-aortic ergonovine maleate $0.1-0.2 \mathrm{mg}$ (maximal $0.3 \mathrm{mg}$ in total). Among 98 patients, 11 showed spasm. One of these patients had old myocardial infarction and they reported serious arrhythmias (ventricular tachycardia or complete heart block) in 7 subjects. I occasionally discuss with cardiologists who consider that provocation of spasm after routine diagnostic coronary arteriography is not useful because nitrate used at angiographic study might hinder provocative test. It is very erroneous: cardiologists should read reports in 1970-80s.

I ordinarily use ergonovine maleate $0.2 \mathrm{mg}$ (either intravenous or intra-aortic injection). When blood pressure is high, I use intracoronary injection of $0.01-0.02 \mathrm{mg}$ (ergonovine rise blood pressure 20-50 $\mathrm{mmHg}$ ).

\section{Acetylcholine}

In comparison to ergonovine, sensitivity for provocation of coronary vasospasm is superior but if vasospasm induced with intracoronary acetylcholine is not occlusive, diagnosis is not so sure (less specificity as compared with ergonovine). Yasue et al. [21] established method of provocation of coronary artery spasm with acetylcholine during angiographic study. They used acetylcholine at first 10 micrograms into a coronary artery and if no spasm was provoked, they increased amount of it gradually; 20-30-50 and finally 100 micrograms. Acetylcholine often causes bradycardia and preventive pacing is often utilized. It is safer but during pacemaker rhythm, observation of ST changes is very difficult. Accordingly, it is better to "switch on" the pacemaker only when heart rate becomes very late. I myself never use pacemaker; only cough by patients is ordinarily enough against slow heart rate.

\section{Serotonin}

Serotonin is one of most strong vasoconstrictor and has been used in a few studies [22, 23]. However, nowadays, it is used only in experimental study using animals due to its potential hazards.

\section{Cold pressure test}

This method was reported by Waters et al. [24]. It may be useful and safe but due to its low sensitivity, this method is used only in few laboratories.

\section{Hyperventilation test}

Hyperventilation test was done by some investigators [25,26]. It was useful to prove excessive alkalization of serum triggers vasospasm. However, as cold pressure test, due to low sensitivity, this test is also performed in few laboratories.

\section{Complications on spasm provocation}

As described in the history and definition, spasm itself, if prolonged, even in coronary artery without apparent narrowing, can trigger myocardial infarction. And even short spasm can cause serious arrhythmias. Accordingly, cardiologists must be ready to all these complications. Ergonovine maleate, if administered with intravenous 
or intra-aortic injection, causes multiple spasms and can cause so called "electro-mechanical dissociation". Immediate external cardiac massage and intracoronary and/or intra-aortic, intravenous nitrate are necessary. And, as the effect of ergonovine maleate is longer than acetylcholine, spasm can appear after it is resolved once with nitrate. I usually give dermal nitrate, calcium blockers and occasionally nicorandil $10-15 \mathrm{mg}$ to patients with positive response to ergonovine immediately after the angiographic study and give 10-20 tablets of sublingual nitrate as soon as they returned to the ward. Effect of acetylcholine is short and after resolve of spasm, delayed complication is rare. It occasionally causes atrial fibrillation. Usually, atrial fibrillation vanishes spontaneously or relatively easily with anti-arrhythmic agents.

\section{Treatment}

Of course, in cases with critical coronary narrowings, treatment with percutaneous coronary interventions and/or coronary artery bypass is performed routinely.

For medical treatment, calcium antagonists, nicorandil and/or long acting nitrates are used. Long acting nitrate, especially transdermal, is very useful when patients forget drugs or cannot take drugs due to gastric disorders. Of course, if patients have some risk factors such as diabetes, hypertension, high uric acid and hyperlipemia, treatment for these factors is also necessary. It is common to use aspirin in patients with mild coronary narrowings. Yasue et al. [27] reported that statin(s) reduced attack of chest pain. And, as I reported [28], smoking is one of most important cause of vasospasm, emphasis to stop of smoking is very important.

As calcium antagonists, especially diltiazem, can cause bradycardia, I use nicorandil at first in patients with slow heart rate. Cardiologists must teach to patients having this disease, even if they are given long acting nitrate, to carry oral (sublingual or spray) nitrate in any instance and to use it in even mild chest discomfort.

And, although not so frequent, patients who have migraine also, cardiologists must consult to neurologists as for treatment because many drugs for migraine have vasoconstrictive action which is similar to ergonovine.

\section{Intractable cases}

Some patients without significant coronary narrowings have frequent chest pain despite maximal doses of calcium blockers, nicorandil and nitrates. Denopamine [29] and /or alpha-blocker [30] are reported to be effective at least partially.

\section{Beta blockers}

Beta blockers are, of course, effective to suppress attacks of effort angina and also used for treatment of hypertension. However, propranolol was proved to aggravate symptoms [31] of vasospasm and although not so frequent, induces acute myocardial infarction [32]. This fact is very important in clinical practice; if cardiologists cannot rule out vasospasm as chest discomfort of patients, they should not use beta blocker.

\section{Prognosis}

It is very difficult to predict the prognosis of patients with variant angina. Of course, subjects with critical narrowing, if they are not treated with percutaneous coronary interventions or bypass surgery, have more major cardiac events. Patients without significant narrowing, in general, have better prognosis if they were treated by experienced cardiologists. I reported that prognosis of subjects with "normal" coronary arteries is better than those with mild-moderate coronary narrowings [9]. In that study, I reported results of follow-up $11.7 \pm 6.8$ years in 1,248 patients of variant angina without coronary narrowing more than $50 \%$. Ninety-one subjects $(7.3 \%)$ developed effort angina, unstable angina or acute myocardial infarction and all of these patients had coronary narrowing more than $75 \%$ in the follow up coronary angiography. Thirty-one (2.4\%) died suddenly. Multivariate analysis showed that the presence of coronary stenosis, even if trivial, made the prognosis worse $(\mathrm{p}=0.027$, odds ratio 1.66 , confidence interval 1.06 2.61). As one of diverse aspect of vasospasm, some patients are free of any symptoms without any medications. However, cardiologists should follow patients with vasospasm using drugs involving calcium antagonists even in subjects who have no chest discomfort for more than several years after diagnosis [33].

\section{Conclusion}

As described in introduction, I cannot understand why many cardiologists have no concern to coronary vasospasm. However, variant angina, even in the absence of coronary narrowing on angiography, can cause acute myocardial infarction and fatal arrhythmias. Cardiologists must study more on this serious disease and establish better method of treatment of patients with vasospasm.

\section{References}

1. Pristipino C, Beltrame JF, Finocchiaro ML, Hattori R, Fujita M, et al. (2000) Major racial differences in coronary constrictor response between japanese and caucasians with recent myocardial infarction. Circulation 101: 1102-1108.

2. Prinzmetal M, Kennamer R, Merliss R, Wada T, Bor N (1959) Angina pectoris I. A variant form of angina pectoris; preliminary report. Am J Med 27: 375-388.

3. Roberts WC, Curry RC, Isner JM, Waller BF, McManus BM, Mariani-Constantin R, Ross AM (1982) Sudden Death in Prinzmetal's Angina With Coronary Spasm Documented by Angiography: Analysis of Three Necropsy Patients. Amer J Cardiol 50: 203-210

4. Sones FM Jr, Shirey EK (1962) Cine coronary arteriography. Mod Concepts Cardiovasc Dis 31: 735-738.

5. Oliva PB, Potts DE, Pluss RG (1973) Coronary arterial spasm in Prinzmetal angina. Documentation by coronary arteriography. N Engl J Med 288: 745-751.

6. Cheng TO, Bashour T, Kelser GA Jr, Weiss L, Bacos J (1973) Variant angina of Prinzmetal with normal coronary arteriograms. A variant of the variant. Circulation 47: 476-485.

7. Schroeder JS, Bolen JL, Quint RA, Clark DA, Hayden WG, et al. (1977) Provocation of coronary spasm with ergonovine maleate. New test with results in 57 patients undergoing coronary arteriography. Am J Cardiol 40: 487-491.

8. Heupler FA Jr, Proudfit WL, Razavi M, Shirey EK, Greenstreet R, et al. (1978) Ergonovine maleate provocative test for coronary arterial spasm. Am J Cardiol 41: 631-640.

9. Takatsu F, Watarai M (2011) Mild stenosis makes prognosis of vasospastic angina worse. Coron Artery Dis 22: 1-5.

10. Puddu P, Bourassa MG, Waters DD, Lesperance J. Sudden Death in Two Patients with Variant Angina and Apparently Minimal Fixed Coronary Stenoses. J Electrocardiology 1983; 16: 213-220.

11. Nakamura M, Takeshita A, Nose $Y(1987)$ Clinical characteristics associated with myocardial infarction, arrhythmias, and sudden death in patients with vasospastic angina. Circulation 75: 1110-1116.

12. Szlachcic J, Waters DD, Miller D, Théroux $P$ (1984) Ventricular arrhythmias during ergonovine-induced episodes of variant angina. Am Heart J 107: 20-24.

13. Black AJ, Mews GC (1984) Coronary artery spasm after coronary bypass grafting. Am J Cardiol 54: 670-671.

14. Waters DD, Theroux P, Crittin J, Dauwe F, Mizgala HF (1980) Previously undiagnosed variant angina as a cause of chest pain after coronary artery bypass surgery. Circulation 61: 1159-1164. 
Citation: Fumimaro Takatsu MD (2015) Variant Angina: Why do you Ignore Spasm of Coronary Arteries?. Cardiol Pharmacol 4: 143. doi:10.4172/23296607.1000143

15. Specchia G, de Servi S, Falcone C, Bramucci E, Angoli L, et al. (1979) Coronary arterial spasm as a cause of exercise-induced ST-segment elevation in patients with variant angina. Circulation 59: 948-954.

16. Curry BC, Pepine CJ, Sabom MB, Feldman RL, Christie LG, Conti R(1977) Effects of Ergonovine in Patients with and without Coronary Artery Disease. Circulation 56: 803-809.

17. Yasue H, Takizawa A, Nagao M, Nishida S, Horie M, et al. (1988) Long-term prognosis for patients with variant angina and influential factors. Circulation 78: $1-9$

18. Takizawa A, Yasue H, Omote S, Nagao M, Hyon H, et al. (1984) Variant angina induced by alcohol ingestion. Am Heart J 107: 25-27.

19. Higgins CB, Wexler L, Silverman JF, Schroeder JS (1976) Clinical and arteriographic features of Prinzmetal's variant angina: documentation of etiologic factors. Am J Cardiol 37: 831-839.

20. Takatsu F, Osugi J, Sugiishi M, Suzuki A, Nagaya T (1989) Intercoronary and Intracoronary Communications in Four Cases of Vasospastic Angina. Catheterization and Cardiovascular Diagnosis 16: 103-108

21. Yasue $H$, Horio $Y$, Nakamura N, Fujii H, Imoto N, Sonoda R, Kugiyama $K$, et al. Induction of coronary artery vasospasm by acetylcholine in patients with variant angina: possible role of the parasympathetic nervous system in the pathogenesis of coronary artery vasospasm. Circulation 1986; 74: 955-65.

22. McFadden EP, Clarke JG, Davies GJ, Kaski JC, Haider AW, et al. (1991) Effect of intracoronary serotonin on coronary vessels in patients with stable angina and patients with variant angina. N Engl J Med 324: 648-654.

23. Mongiardo R, Finocchiaro ML, Beltrame J, Pristipino C, Lombardo A, et al. (1996) Low incidence of serotonin-induced occlusive coronary artery spasm in patients with recent myocardial infarction. Am J Cardiol 78: 84-87.
24. Waters DD, Szlachcic J, Bonan R, Miller DD, Dauwe F, et al. (1983) Comparative sensitivity of exercise, cold pressor and ergonovine testing in provoking attacks of variant angina in patients with active disease. Circulation 67: 310-315.

25. Fujii $\mathrm{H}$, Yasue $\mathrm{H}$, Okumura $\mathrm{K}$, Matsuyama K, Morikami $\mathrm{Y}$, Miyagi $\mathrm{H}$, Ogawa $\mathrm{H}$ (1988) Hyperventilation-Induced Simultaneous Multivessel Coronary Spasm in Patients With Variant Angina: An Echocardiographic and Arteriographic Study. JACC 12: 1184-1192.

26. Previtali M, Ardissino D, Barberis P, Panciroli C, Chimienti M, et al. (1989) Hyperventilation and ergonovine tests in Prinzmetal's variant angina pectoris in men. Am J Cardiol 63: 17-20.

27. Yasue H, Mizuno Y, Harada E, Itoh T, Nakagawa H, et al. (2008) Effects of a 3-Hydroxy-3-Methylglutaryl Coenzyme A Reductase Inhibitor, Fluvastatin, on Coronary Spasm After Withdrawal of Calcium-Channel Blockers. JACC 51: 1742-1748.

28. Sugiishi M, Takatsu F (1993) Cigarette smoking is a major risk factor for coronary spasm. Circulation 87: 76-79.

29. Shimizu H, Lee JD, Ogawa KB, Sugiyama T, Yamamoto M, et al. (1991) Refractory variant angina relieved by denopamine--a case report. Jpn Circ J 55: 692-694.

30. Julius BK, Vassalli G, Mandinov L, Hess OM (1999) Alpha-adrenoceptor blockade prevents exercise-induced vasoconstriction of stenotic coronary arteries. J Am Coll Cardiol 33: 1499-1505.

31. Tilmant PY, Lablanche JM, Thieuleux FA, Dupuis BA, Bertrand ME (1983) Detrimental effect of propranolol in patients with coronary arterial spasm countered by combination with diltiazem. Am J Cardiol 52: 230-233.

32. Vincent GM, Anderson JL, Marshall HW (1983) Coronary spasm producing coronary thrombosis and myocardial infarction. N Engl J Med 309: 220-223.

33. Bott-Silverman C, Heupler FA Jr (1983) Natural history of pure coronary artery spasm in patients treated medically. J Am Coll Cardiol 2: 200-205. 